\title{
Performance Comparison Of Shunt Rf Mems Switches
}

\section{S Girish Gandhi ${ }^{1}$, I Govardhani ${ }^{2}$, M Venkata Narayana ${ }^{3}$, K Sarat Kumar ${ }^{4}$}

\author{
${ }^{1234}$ Department of Electronics and communication engineering, Koneru Lakshmaih Education Foundation-KLEF \\ (Deemed to be University), Green Fields, Vaddeswaram, Guntur-522502, India. \\ 1'girishgandhi.s@gmail.com, ${ }^{2}$ govardhanee_ec@kluniversity.in
}

Article History: Received: 11 January 2021; Accepted: 27 February 2021; Published online: 5 April 2021

\begin{abstract}
This is an attempt to compare three different shunt configured RF MEMS switches which offers a choice for applications in satellite and antennas. Advanced RF communication domain demands for design and modeling of RF MEMS switch which provides extremely reduced pull-in voltage, better isolation, low insertion loss, and with greater reliability. The proposed work manages with comparison of design modeling and performance of three different shunt configured RF MEMS switches. The proposed shunt configured RF MEMS switches are designed with different dimensions with different meandering techniques with perforations on beam structure helps in reducing the amount of voltage required for actuation of switch which is known as pull-in voltage. Comparative study of three different RF MEMS switches which involves in conducting electromechanical analysis are carried out using COMSOL multi physics tool and electromagnetic analysis are carried out using HFSS tool. Moreover the comparative study involves in comparing the values of pull-in voltage, switching time and capacitance, stress, insertion loss, return loss and isolation of three different RF MEMS switches. Proposed first switch model derives pull-in voltage of $16.9 \mathrm{v}$ with the switching time of $1.2 \mu \mathrm{s}$, isolation of $47.70 \mathrm{~dB}$ at $5 \mathrm{GHz}$ and insertion loss of $0.0865 \mathrm{~dB}$ and return loss of $41.55 \mathrm{~dB}$. Proposed second switch model derives pull-in voltage of $18.5 \mathrm{v}$ with the switching time of $2.5 \mu \mathrm{s}$, isolation of $37.20 \mathrm{~dB}$ at $8 \mathrm{GHz}$ and insertion loss of $0.1177 \mathrm{~dB}$ and return loss of $38.60 \mathrm{~dB}$. Proposed third switch model delivers pull-in voltage of $18.75 \mathrm{v}$ with the switching time of $2.56 \mu \mathrm{s}$, isolation of $44.1552 \mathrm{~dB}$ at $8 \mathrm{GHz}$ and insertion loss of $0.0985 \mathrm{~dB}$ and return loss of $42.1004 \mathrm{~dB}$.
\end{abstract}

Keywords: MEMS switch, meanders, anchors, COMSOL, HFSS.

\section{Introduction}

The MEMS mainly attributes to the concept of miniaturization which is creating smaller structures than the present ones without any compromise in the performance of the system. This RF MEMS switches are the minute versions of the normal conventional switches. This technology has been widely developed in the last decades of 20th century [1]. The RF MEMS switches are widely used in many practical versions like in temperature sensors, pressure measuring equipments, accelerometers, Gyro scopes etc [2]. The size of the RF MEMS switches is very less which is at to be in microns. All the equipment of the switches will be fabricated on a single semiconductor chip. The basic function of the RF MEMS switches are those to drive the signals through transmission paths [3]. This RF MEMS switches had Rapid development in the industrial sector and community ways. As they are very comfortable and constrained to the required system applications those are mainly used in wireless communication and space communication systems. These are the metallic structures with the capacitive configurations. As MEMS switches are well structured without any compromise in the switching mechanisms. So these has greater performance than the normal conventional switches. These switches are also configurable as required in the mechanical and electrical properties. As the mechanism and the performance of these RF MEMS switches are same to the normal conventional switches we can say that this replaces the pin diodes and transistors for switching mechanism used in the previous decades [4]. To match out the RF MEMS switches they were technically tested in electrical and mechanical outlines [5]. As the MEMS technology is advanced technology which gives the reduced versions in size and also compatible in the smaller systems with the reduced cost we had many advantages like the size will be reduced and also the pull in voltage range will be reduced. We can also observe the enhanced RF performance. This RF MEMS switches are very reliable by having good lifetime [6]. They also has low resistance losses which comprises with less power consumption. This RF MEMS switches are widely flexible in multiband frequencies with good linearity [7]. As all these are slightly beneficial to the system. These are also being implemented in the satellites and military applications.

\section{Materials and Methods}

In MEMS structures to equip all the materials on the single chip the base is very important. Here the base represents the substrate used in the MEMS structure. Substrate plays a crucial role in the performance system. Generally in MEMS use many substrate materials like silicon, glass, quartz many other semiconductor materials, even though there are many materials mainly prefer the silicon substrate [8]. These Silicon wafers are very much suitable and flexible to design microstructures. In MEMS structures we also mainly concentrate on the dielectric materials which has an eminent role while dealing with the frequency systems. So in RF MEMS switch the dielectric used is Silicon nitride which is very much suitable to required fabrication process. Generally this 
silicon nitride has many properties like diffusion over the solvents and also it will be more stable over wide range of temperatures. It does not get effected the process of oxidation and also provided a better electric constant. For the meanders and beams structures we choose a good conductive metal like gold [9]. By considering meanders we can estimate the spring constant which is more beneficial to the stiffness factor in design. Based on the material selected the required properties are adjusted to give maximum performance and also by choosing perfect fabricating materials we can improve the switching mechanism in RF MEMS switches. We also use any alternative materials required applications and properties.

\section{RF MEMS Switch}

The RF MEMS switches are very much beneficial than then the normal semiconductor switches like having less size, reduced pull in voltage, enhance the order of RF performance, more reliable and larger lifetime. It has low resistance losses, the power consumption for the RF MEMS switches is also very less it is also best insolated switch so it is used in the wide range of RF and microwave frequencies. The size is very much less as microns. It also has a good capacitive mechanism when compared to the conventional semiconductor switches [10]. The main principle of the RF MEMS switches is it drives the signal through the transmission parts movement of the switch decides whether the switch is in open circuit or short circuit in the transmission line of radio frequencies [11]. Mainly this RF MEMS switches classified into two types like series switch and shunt switch. In series switch starting stages it will be in off conditions since is no biasing voltage. In series RF switches isolation capacities are maximum. The radio frequency signal passes through the input signal up to the output signal. Whereas shunt type RF MEMS switch will be in on condition initially. This capacitive switch where there is a beam structure with moving electrode [12]. In this switch the transmission of the signal takes place when the switch is open from the input to output.

\section{Proposed Switch}

The proposed three RF MEMS switches are shunt type capacitive activated. The proposed Switches are modeled by best choosing silicon as a substrate material having a length of $450 \mu \mathrm{m}$, switches are associated with CPW, Ground and Signal line. Beam is clearly separated from signal dielectric with air gap and this air gap establishes a capacitive effect [13]. Anchors are used to fix the Beam between two ends. Beam with Perforations on the beam helps in reducing pull in voltage [14]. The proposed shunt RF MEMS switch schematics are show in fig $1,2 \& 3$ and its design specifications are listed in table $1,2 \& 3$.

\begin{tabular}{|c|c|c|c|c|}
\hline Parameters & $\begin{array}{c}\text { Length } \\
(\mu \mathrm{m})\end{array}$ & $\begin{array}{c}\text { Width } \\
(\mu \mathrm{m})\end{array}$ & $\begin{array}{c}\text { Thickness } \\
(\mu \mathrm{m})\end{array}$ & Materials \\
\hline Substrate & 450 & 400 & 4543 & $\mathrm{Si}$ \\
\hline Oxide layer & 450 & 400 & 100 & $\mathrm{SiO}_{2}$ \\
\hline $\begin{array}{c}\text { CPW } \\
\text { ground }\end{array}$ & 151.5 & 400 & 100 & Gold \\
\hline $\begin{array}{c}\text { CPW signal } \\
\text { line }\end{array}$ & 67 & 400 & 100 & $\mathrm{Goll}$ \\
\hline $\begin{array}{c}\text { Dielectric } \\
\text { layers }\end{array}$ & 67 & 67 & 0.1 & $\mathrm{Si}_{3} \mathrm{~N}_{4}$ \\
\hline Anchors & 30 & 80 & 1 & $\mathrm{Au}$ \\
\hline Beam & 120 & 44 & 5 & $\mathrm{Au}_{2} \mathrm{Cu}_{\mathrm{N}} \mathrm{Ni}$ \\
\hline Meander d & 10 & 25 & 5 & $\mathrm{Au}_{\mathrm{n}} \mathrm{Cu} . \mathrm{Ni}$ \\
\hline $\mathrm{C}$ & 30 & 10 & 5 & \\
\hline $\mathrm{B}$ & 10 & 35 & 5 & \\
\hline $\mathrm{A}$ & 25 & 12 & 5 & \\
\hline
\end{tabular}

Table 1: Design Specifications of Switch 1

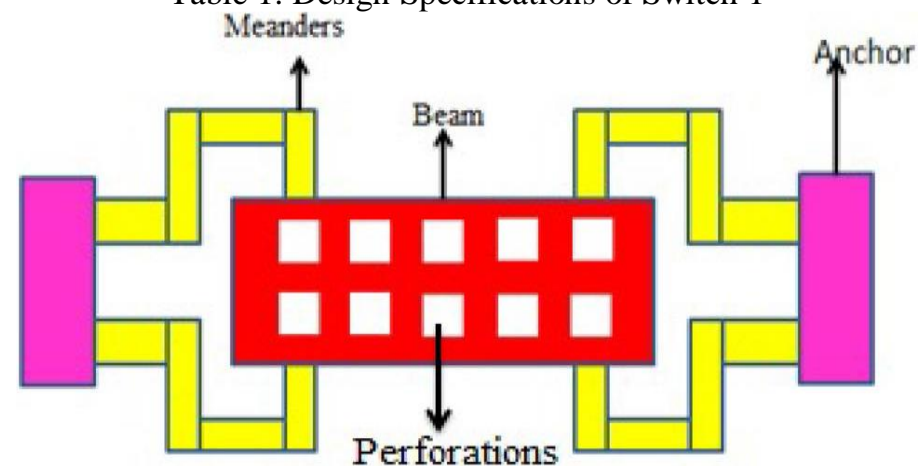

Fig: Proposed Switch 1 


\begin{tabular}{|c|c|c|c|c|}
\hline Parameters & $\begin{array}{c}\text { Length } \\
(\mu \mathrm{m})\end{array}$ & $\begin{array}{c}\text { Width } \\
(\mu \mathrm{m})\end{array}$ & $\begin{array}{c}\text { Thickness } \\
(\mu \mathrm{m})\end{array}$ & Materials \\
\hline Substrate & 450 & 400 & 4543 & $\mathrm{Si}$ \\
\hline Oxide layer & 450 & 400 & 100 & $\mathrm{Si}_{3} \mathrm{~N}_{4}$ \\
\hline $\begin{array}{c}\text { CPW } \\
\text { Ground }\end{array}$ & 150 & 400 & 100 & $\mathrm{Gold}$ \\
\hline $\begin{array}{c}\text { CPW signal } \\
\text { line }\end{array}$ & 65 & 400 & 100 & $\mathrm{Gold}$ \\
\hline $\begin{array}{c}\text { Dielectric } \\
\text { Layer }\end{array}$ & 65 & 65 & 0.5 & $\mathrm{Si}_{3} \mathrm{~N}_{4}$ \\
\hline Anchors & 30 & 80 & 5 & $\mathrm{Au}$ \\
\hline Beam & 120 & 44 & 1.5 & $\mathrm{Au}$ \\
\hline Meander 1 & 10 & 30 & 1.5 & $\mathrm{Au}$ \\
\hline Meander 2 & 30 & 10 & 1.5 & $\mathrm{Au}$ \\
\hline
\end{tabular}

Table 2: Design Specifications of Switch 2

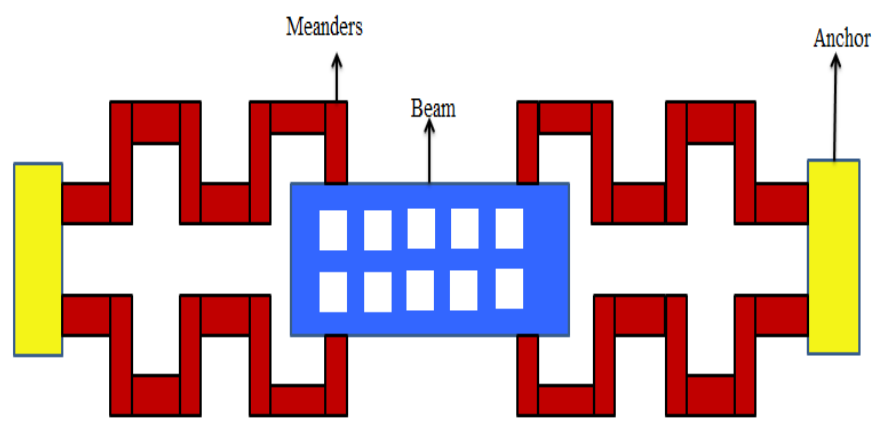

Fig2: Proposed Switch 2

\begin{tabular}{|c|c|c|c|c|}
\hline Component & $\begin{array}{c}\text { Length } \\
(\boldsymbol{\mu} \mathbf{m})\end{array}$ & $\begin{array}{c}\text { Width } \\
(\boldsymbol{\mu m})\end{array}$ & $\begin{array}{c}\text { Thickness } \\
(\boldsymbol{\mu m})\end{array}$ & Material \\
\hline Substrate & 450 & 400 & 4543 & Silicon \\
\hline Oxide layer & 450 & 400 & 100 & Sio2 \\
\hline $\begin{array}{c}\text { Dielectric } \\
\text { layer }\end{array}$ & 66 & 66 & 0.5 & Si3N4 \\
\hline CPW line & 151 & 400 & 100 & Gold \\
\hline Signal line & 66 & 400 & 100 & Gold \\
\hline Beam & 120 & 44 & 3.5 & Gold \\
\hline Meander a & 10 & 30 & 3.5 & Gold \\
\hline Meander b & 30 & 10 & 3.5 & Gold \\
\hline Anchor & 30 & 80 & 4.5 & Gold \\
\hline
\end{tabular}

Table 3: Design Specifications of Switch 3 


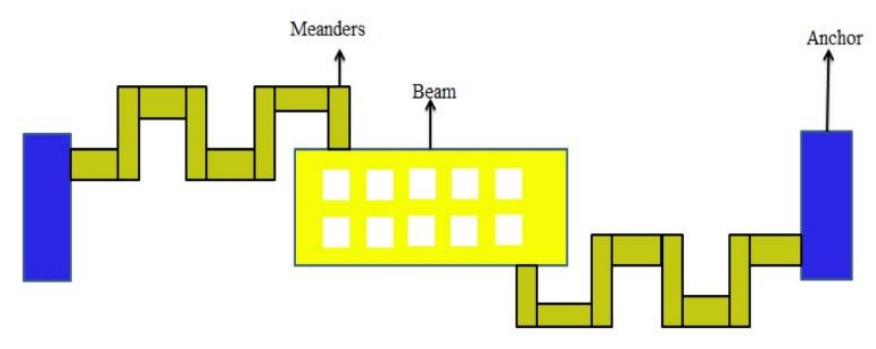

Fig 3: Proposed Switch 3

\section{Results and Discussion}

The proposed beam structured capacitive RF shunt MEMS switch is simulated on COMSOL software tool \& HFSS Simulator tool.

\subsubsection{Spring Constant (K):}

Spring constant is key factor for analyzing mechanical behavior of proposed switches. Spring constant of the proposed switch depends on beams stiffness [15].

$$
k=\frac{E w t^{3}}{l^{3}}
$$

\subsubsection{Pull in Voltage (Vp):}

With the pull-in voltage switch can beelectro statically actuated. The voltage needed for activating the switch is actuation voltage, and it mainly relay on the spring constant $(\mathrm{K})$. The switching on and off utilizes small amount of DC voltage, which helps in making beam to contact with signal dielectric layer [16-17].

The mathematical expression for pull-in voltage $(\mathrm{Vp})$ is,

$$
V_{P}=\sqrt{\frac{8 k g_{0}^{3}}{27 \varepsilon_{0} A}}
$$

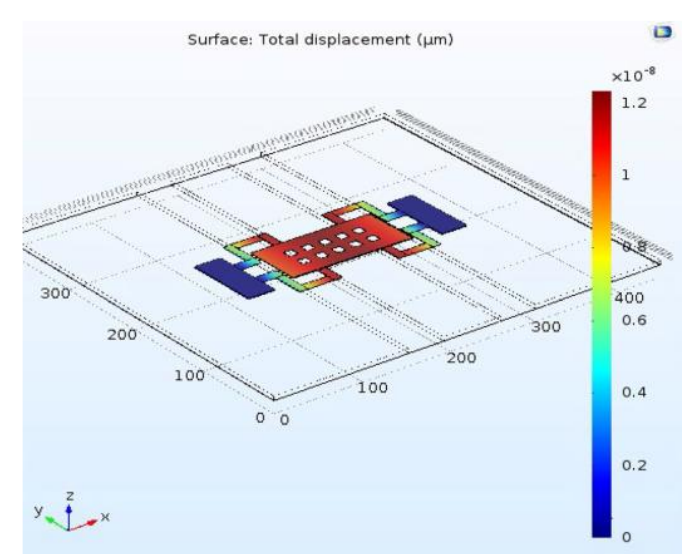

Fig 3: Electromechanical analysis of shunt RF MEMS switch 1

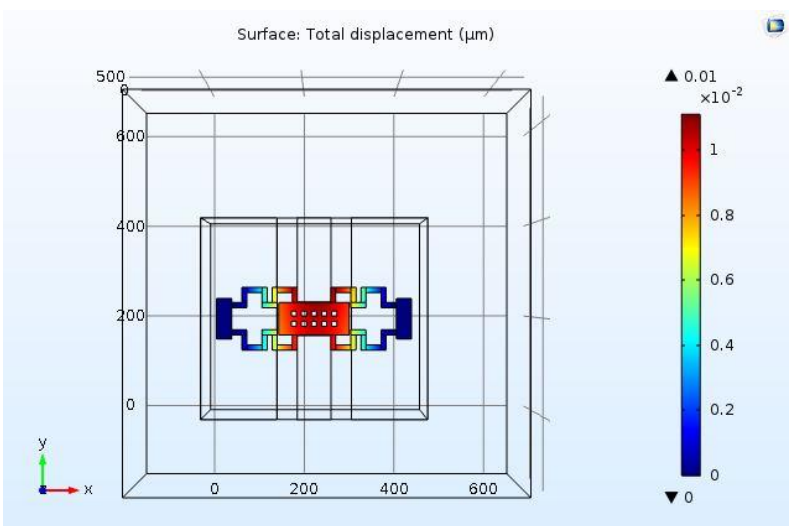

Fig 3: Electromechanical analysis of shunt RF MEMS switch 2 


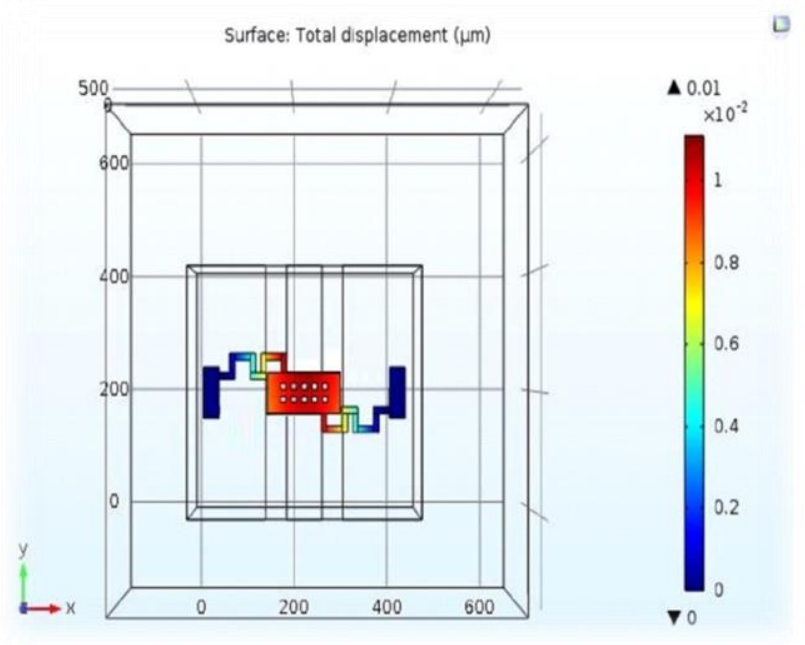

Fig 3: Electromechanical analysis of shunt RF MEMS switch 3

The electromechanical analysis, shows that how the switch is displacement with particular actuation voltage.

\subsubsection{Capacitance Analysis:}

In RF MEMS switch, the key factor to be taken is Capacitive Analysis. The performance of bridge type switch depends on both up state and down state capacitance. The air gap between beam material and signal dielectric helps to form the up state capacitance, and no air gap indicates down state capacitance. The proposed switch has an upstate capacitance which is equated as:

$$
C_{u}=\frac{\varepsilon_{0} A}{g_{0}+\frac{t_{d}}{\varepsilon_{r}}}
$$

The applied voltage to beam, will make beam to colapse towards down due to electrostatically actuated force [18]. The capacitance which is developed, known as downstate capacitance when the switch is in OFF state condition. The downstate capacitance (Cd) is equated as..

$$
C_{d}=\frac{\varepsilon_{0} \varepsilon_{r} A}{t_{d}}
$$

Here, $\mathfrak{t}_{\mathrm{d}}$ indicates signal dielectric layer material thickness ' $\mathscr{E}_{\mathrm{r}}$ ' indicates beams relative permitivity, ' $\mathscr{E}_{0}$ ' indicates air relativity, and ' $\mathrm{A}$ ' indicates area.

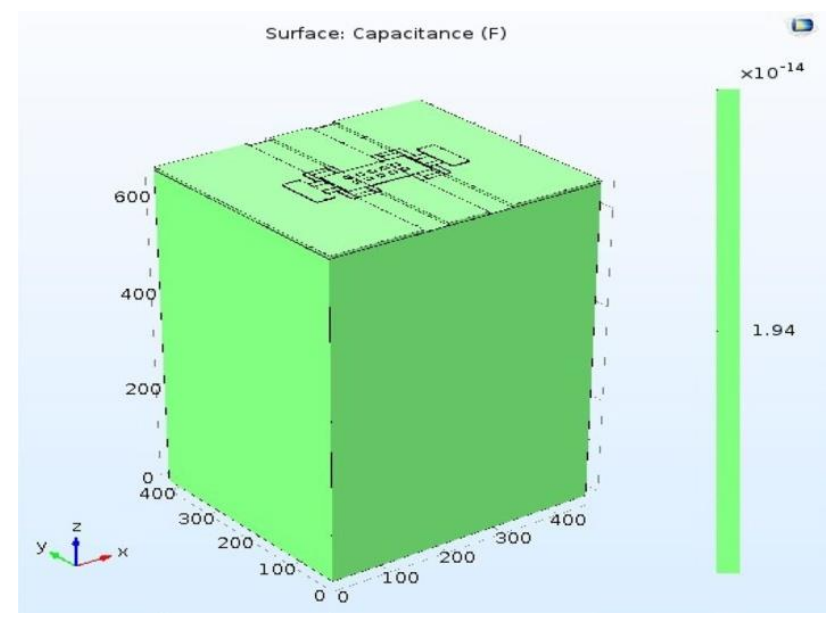

Fig 5: Capacitance analysis of Shunt RF MEMS switch.1 


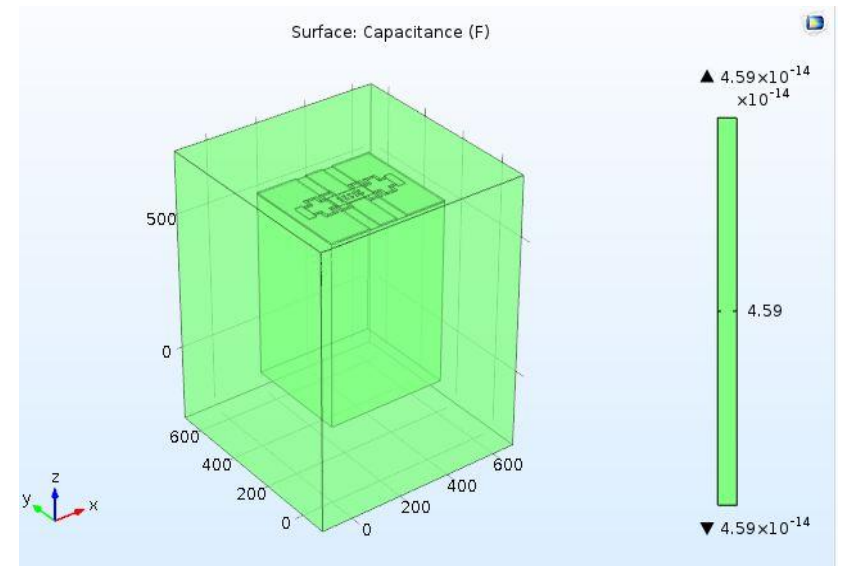

Fig 5: Capacitance analysis of Shunt RF MEMS switch.2

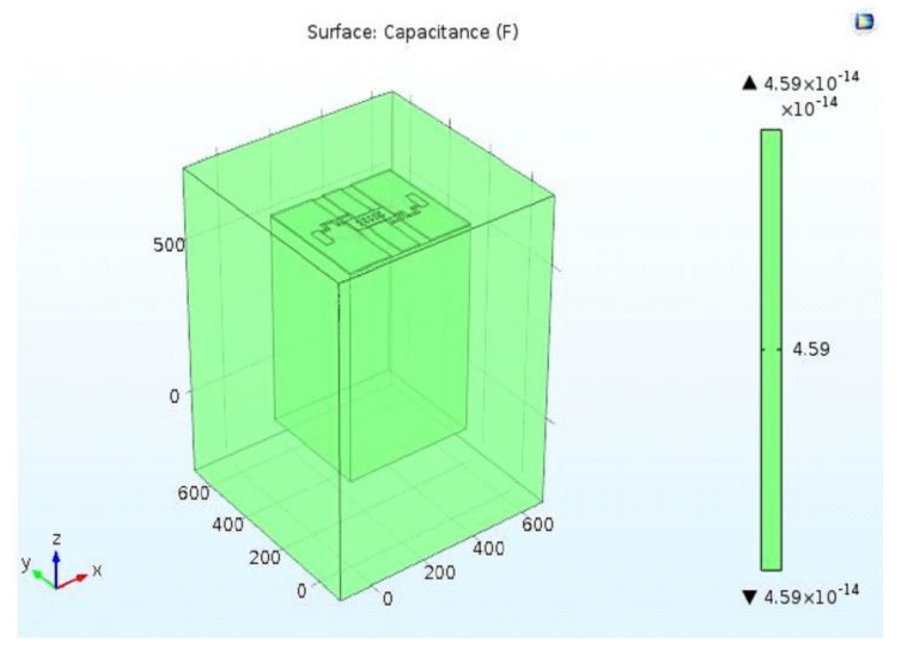

Fig 5: Capacitance analysis of Shunt RF MEMS switch.3

\subsubsection{Switching Time analysis}

The transition speed depend on switching time. This switching time relay on the angular frequency, pull-in voltage (Vp) and supply voltage (Vs) [19].

Switching time is formulated as,

$$
t_{s}=\frac{3.67 V_{p}}{V_{s} \omega_{0}}
$$

\subsubsection{Stress analysis}

The Deformation of switch depends on applied force on the beam, and it is evenly distributed. The stress is anti parallel to the area and direct parallel to the force.

$$
\text { Stress }=\frac{\text { Force }}{\text { Area }}
$$

The Force is formulated as

$$
\text { Force }(f)=\frac{\varepsilon_{0} \varepsilon_{r} V^{2}}{2 d^{2}}
$$

Here,

' $\mathscr{E}_{\mathrm{r}}$ ' indicates beams relative permitivity, ' $\mathscr{E} 0$ ' indicates air relativity, 'l' indicates beam length, 'w' indicates beam width, $d$ indicates air gap from signal line to beam, and ' $V$ ' indicates proposed pull-in voltage( $V p$ ) of 


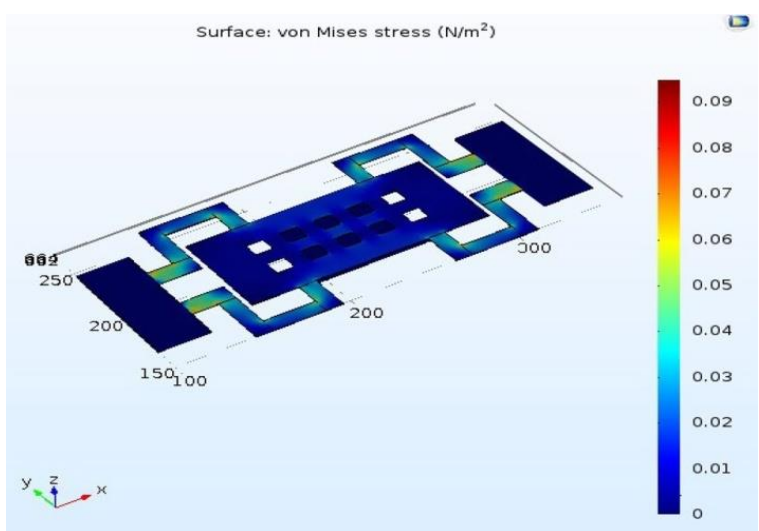

Fig 7: Stress analysis of shunt RF MEMS switch 1

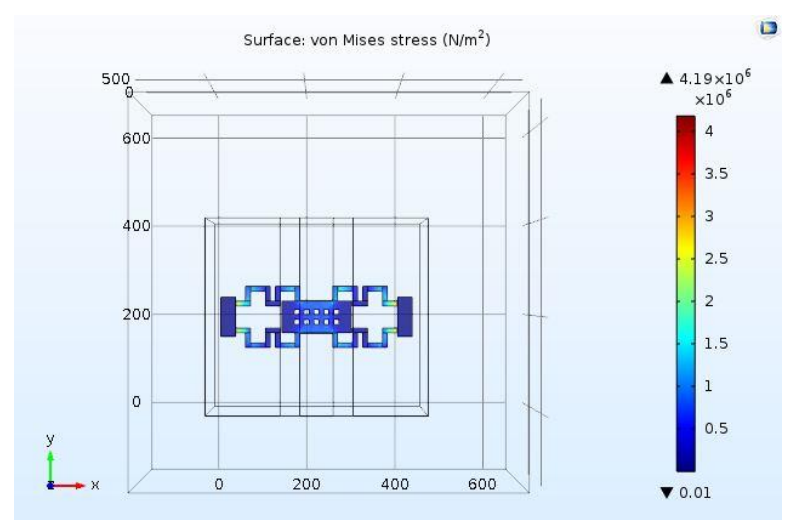

Fig 7: Stress analysis of shunt RF MEMS switch 2

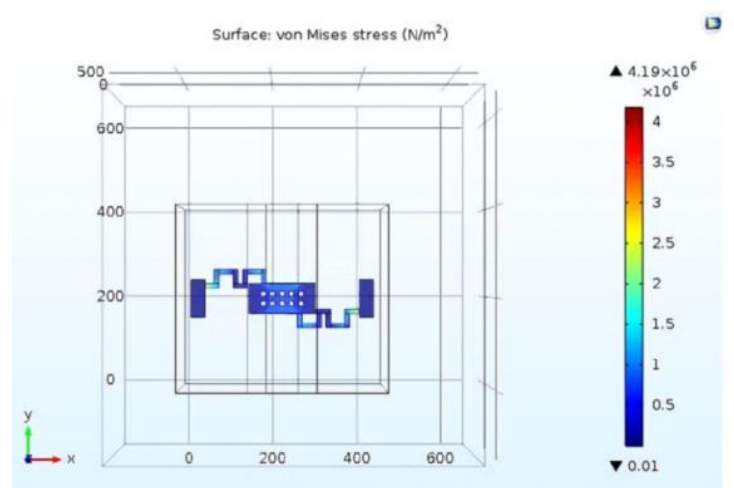

Fig 7: Stress analysis of shunt RF MEMS switch 3

\subsection{ELECTROMAGNETIC ANALYSIS}

The HFSS tool is used for calculating scattering parameters of proposed switches. Return and insertion losses are evaluated during up state condition of switch, whereas isolation is evaluate during down state condition of switch, [20-22].

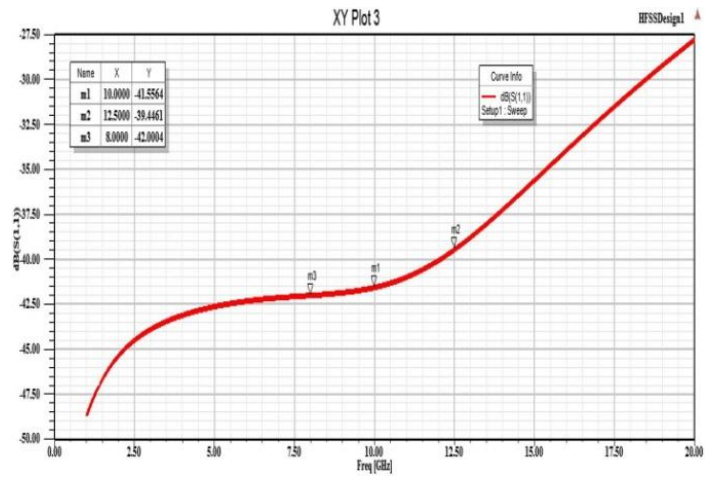

Fig.09. HFFS tool simulated result for Insertion loss of switch 1 


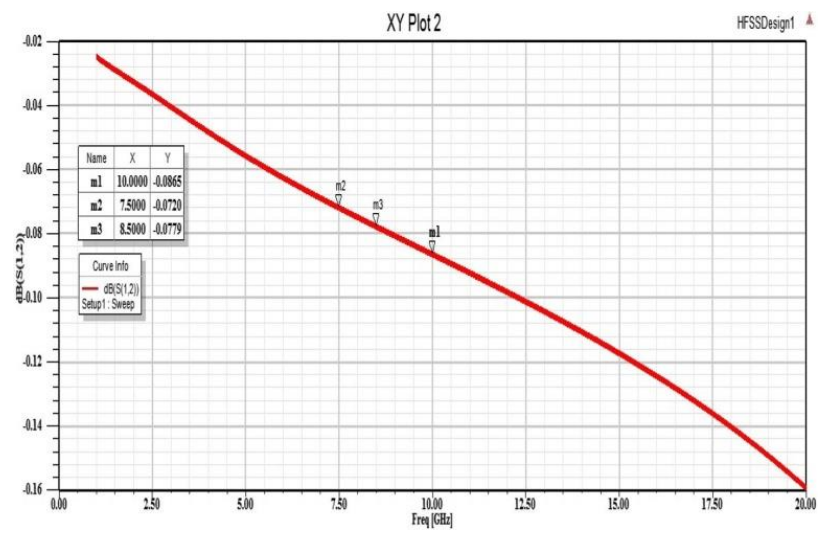

Fig.8. HFSS tool simulated result for Return loss of switch1

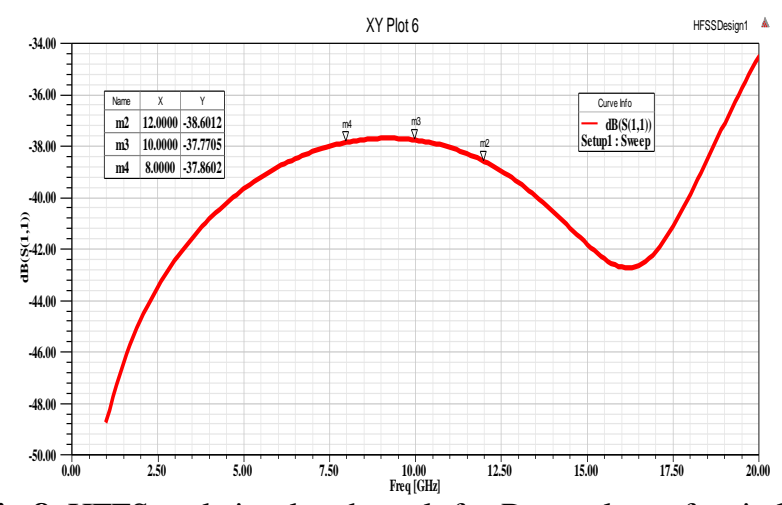

Fig.8. HFFS tool simulated result for Return loss of switch2

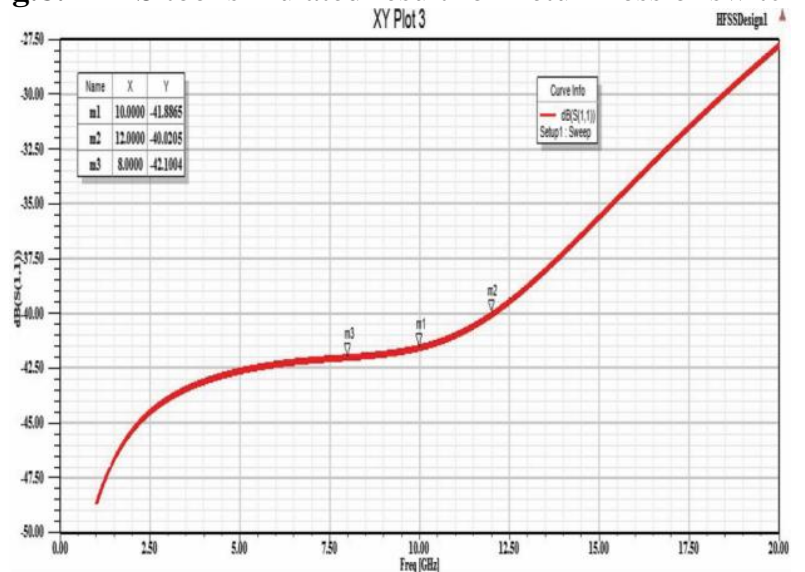

Fig.8. HFFS tool simulated result for Return loss of switch3

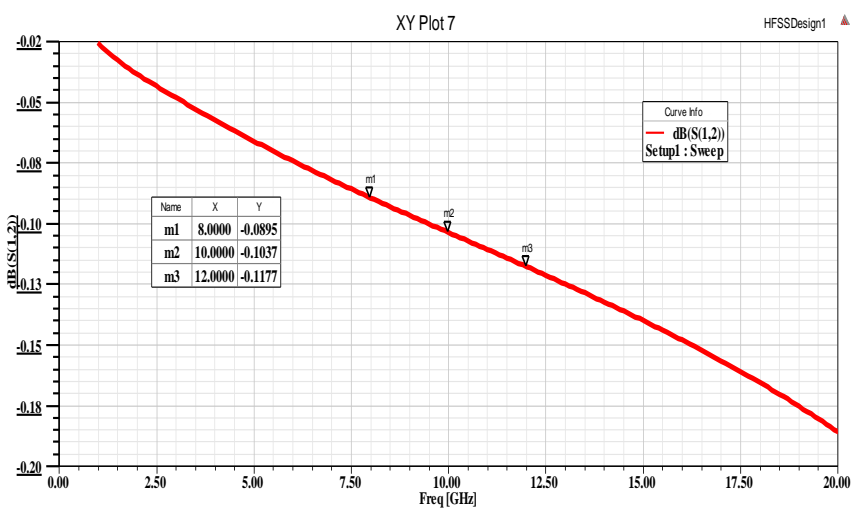

Fig.09. HFFS tool simulated result for Insertion loss of switch 2 


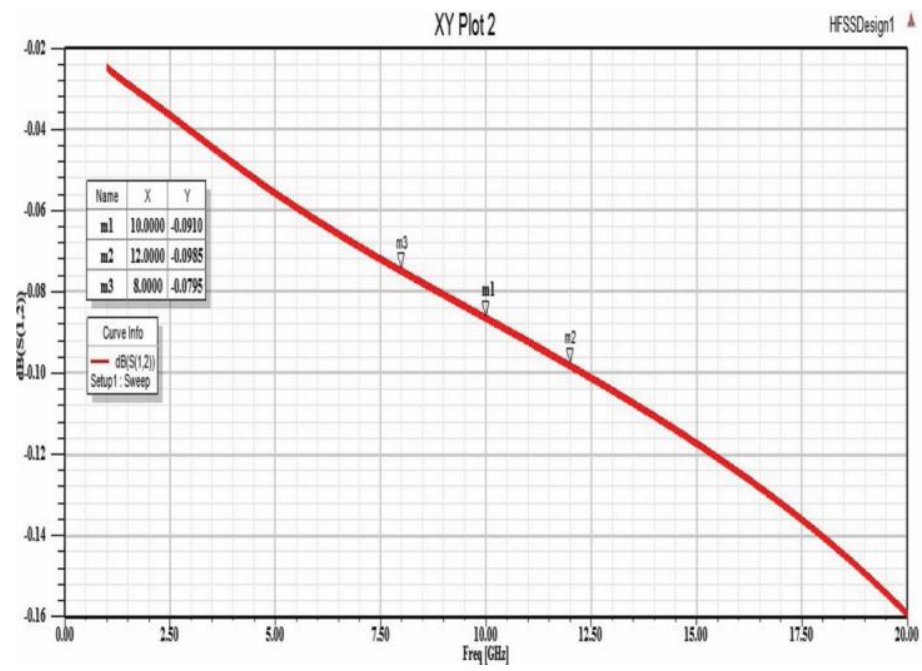

Fig.09. HFFS tool simulated result for Insertion loss of switch 3

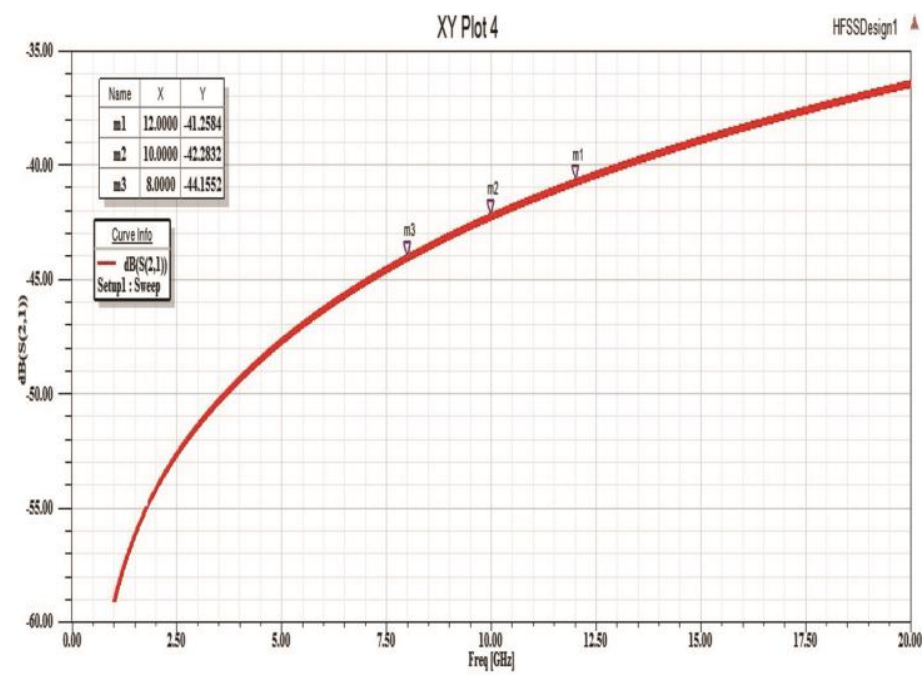

Fig.10. HFFS tool simulated result for Isolation of switch1

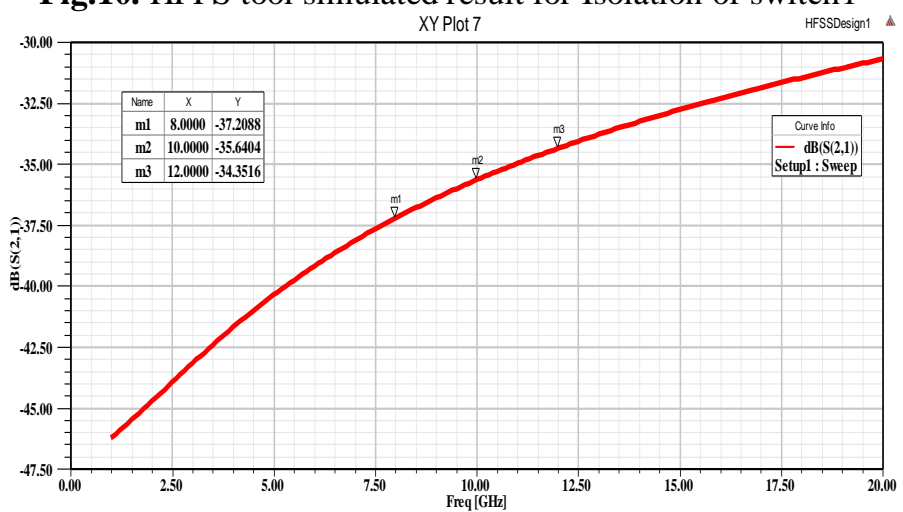

Fig.10. HFFS tool simulated result for Isolation of switch2

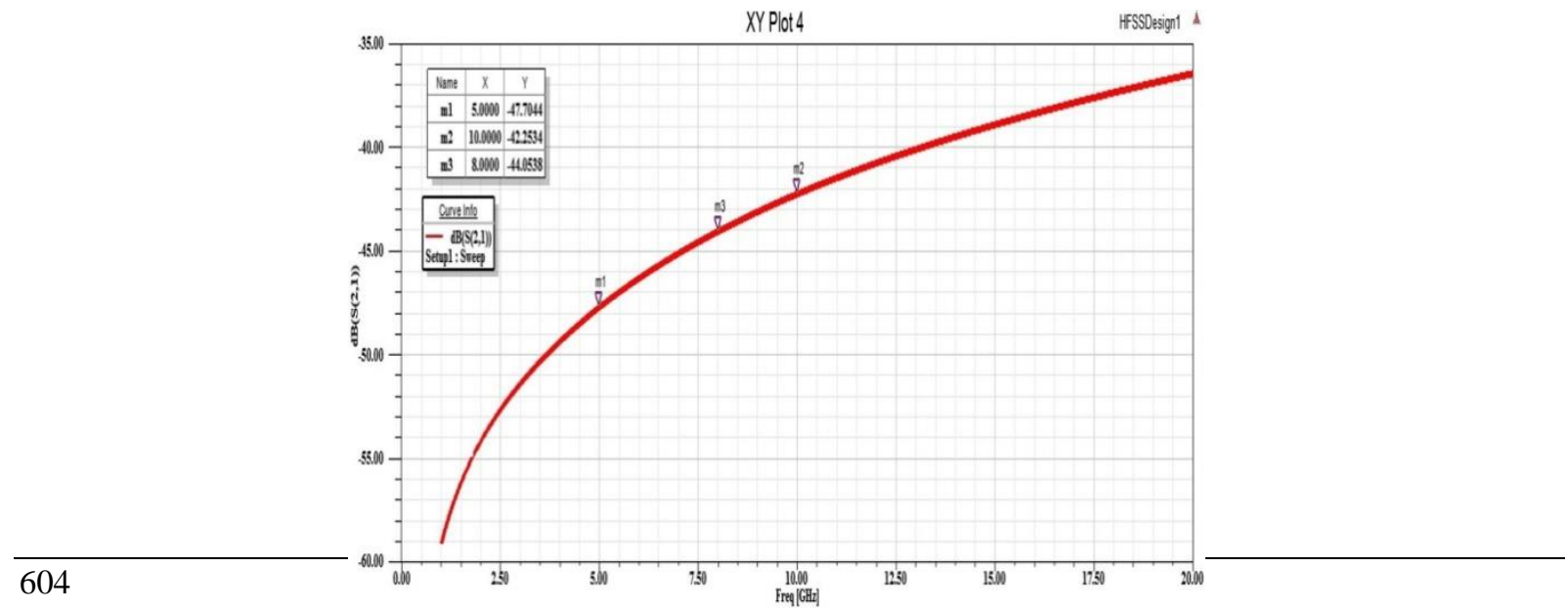


Fig.10. HFFS tool simulated result for Isolation of switch3

\begin{tabular}{|c|c|c|c|c|c|c|}
\hline Parameters & M. Giridhar & $\begin{array}{l}\text { Mafinejad and } \\
\text { Kouzani }\end{array}$ & M. Tang & Proposed Switch 1 & Proposed Switch 2 & Proposed Switch 3 \\
\hline Pull-in (Vp)voltage & $50 \mathrm{~V}$ & $20 \mathrm{~V}$ & $20.4 \mathrm{~V}$ & $16.9 \mathrm{~V}$ & $18.5 \mathrm{~V}$ & $18.75 \mathrm{~V}$ \\
\hline Stress analysis & $\ldots$ & $\ldots$ & $\ldots$ & $1.286 \mathrm{MPa}$ & $4.19 \mathrm{MPa}$ & $4.19 \mathrm{MPa}$ \\
\hline Switching time (ts) & $\ldots$ & $\ldots$ & $25 \mu \mathrm{s}$ & $1.2 \mu \mathrm{s}$ & $2.5 \mu \mathrm{s}$ & $2.56 \mu \mathrm{s}$ \\
\hline Upstate capacitance $(\mathrm{Cu})$ & $\ldots$ & $\ldots$ & $137 \mathrm{fF}$ & $7.46 \mathrm{fF}$ & $5.12 \mathrm{fF}$ & $5.23 \mathrm{fF}$ \\
\hline Downstate capacitance & $\ldots$ & $4.26 \mathrm{pF}$ & $3.9 \mathrm{pF}$ & $1.25 \mathrm{pF}$ & $3.27 \mathrm{pF}$ & $3.32 \mathrm{pF}$ \\
\hline Capacitance ratio & $\cdots$ & $\ldots$ & $\cdots$ & 16.75 & 1.56 & 1.57 \\
\hline Retum Loss $\left(\mathrm{S}_{11}\right)$ & -..- & $24 \mathrm{~dB}$ & -...- & $-41.55 \mathrm{~dB}$ & $-38.60 \mathrm{~dB}$ & $-42.1004 \mathrm{~dB}$ \\
\hline Insertion $\operatorname{Loss}\left(\mathrm{S}_{12}\right)$ & $-0.5 \mathrm{~dB}$ & $0.9 \mathrm{~dB}$ & $-0.46 \mathrm{~dB}$ & $-0.0865 \mathrm{~dB}$ & $-0.1177 \mathrm{~dB}$ & $-0.0985 \mathrm{~dB}$ \\
\hline Isolation $\operatorname{Loss}\left(\mathrm{S}_{21}\right)$ & $-30 \mathrm{~dB}$ & $18 \mathrm{~dB}$ & $-25 \mathrm{~dB}$ & $-47.70 \mathrm{~dB}$ & $-37.20 \mathrm{~dB}$ & $-44.1552 \mathrm{~dB}$ \\
\hline
\end{tabular}

\section{Conclusion}

The design of three different RF shunt MEMS switches is done in this paper. COMSOL software is used for conducting Electromechanical investigation for calculating pull-in voltage and switching time. Proposed Switches $1,2 \& 3$ offers pull-in voltage of $16.9 \mathrm{v}, 18.5 \mathrm{v} \& 18.75 \mathrm{v}$ respectively with the switching time of $1.2 \mu \mathrm{s}$, $2.5 \mu \mathrm{s} \& 2.56 \mu \mathrm{s}$. HFSS tool is used for conducting High frequency analysis. Proposed switches provides isolation of $-47.70 \mathrm{~dB},-37.20 \mathrm{~dB} \&-44.1552 \mathrm{~dB}$ and insertion loss of $-0.0865 \mathrm{~dB}, \quad-0.1177 \mathrm{~dB} \&-$ $0.0985 \mathrm{~dB}$ and return loss of $-41.55 \mathrm{~dB},-38.60 \mathrm{~dB} \&-42.1004 \mathrm{~dB}$. From the results we conclude that the switches are activated at extreme low pull-in voltage which offers high isolation in RF Switch and with improved insertion loss. So, this shunt MEMS switches with extreme low pull-in voltage and enhanced switching speed can be used in many RF applications.

\section{References}

1. Ai Qun Liu., "RF MEMS Switches and Integrated Switching Circuits Design, Fabrication, and Test", Springer, 2010.

2. J. J. Yao and M. F. Chang, "A surface micromachined miniature switch for telecommunications applications with signal frequencies from DC up to $4 \mathrm{GHz}$ ", in International Conference on Solid-State Sensors and Actuators Digest, Stockholm, Sweden, pp. 384-387,1995.

3. J. B. Muldavin and G. M. Rebeiz, "Inline capacitive and DC-contact MEMS shunt switches", IEEE Microwave sWireless Comp. Letters, Vol. 11, No. 8, pp. 334-336, 2001.

4. D. Hyman and M. Mehregany, "Contact physics of gold microcontacts for MEMS switches", IEEE Trans. Comp. Packaging Technology, Vol. 22, No. 3, pp. 357-364, September 1999.

5. W.-B. Zheng, Q.-A. Huang, X.-P. Liao, and F.-X. Li, “RF MEMS membrane switches on GaAs substrates for X-band applications," J. Microelec-tromech. Syst., vol. 14, no. 3, pp. 464_471, Jun. 2005.

6. J. Y. Park, G. H. Kim, K. W. Chung, and J. U. Bu, "Monolithically integrated micromachined RF MEMS capacitive switches," Sens. Actuators A, Phys., vol. 89, pp. 88_94, Mar. 2001.

7. K. S. Rao, L. N. Thalluri, K. Guha, and K. G. Sravani, "Fabrication and characterization of capacitive RFMEMSperforated switch," IEEE Access, vol. 6, pp. 77519_77528, 2018.

8. K. Maninder, K. J. Rangra, D. Kumar, and S. Singh, "Parametric optimization of symmetric toggle RF MEMS switch for X-band applications," Int. J. Recent Trends Eng., vol. 2, p. 95, Nov. 2009.

9. H. Jaafar, K. S. Beh, N. A. M. Yunus, W. Z. W. Hasan, S. Sha_e, and O. Sidek, “A comprehensive study on RF MEMS switch," Microsyst. Technol, vol. 20, no. 2, pp. 2109_2121, Dec. 2014.

10. Hee-Chul Lee, Jae-Yeong Park and Jong-Uk Bu, "Piezo electrically Actuated RF MEMS DC Contact Switches with Low Voltage Operation", IEEE Microwave and wireless components letters; Vol: 15; pp: 202-204; ( 2005).

11. Gustavo P. Rehder, Salvador Mir, Libor Rufer, Emmanuel Simeu, Hoang N. Nguyen, "Low Frequency Test for RF MEMS Switches", IEEE,vol:1, pp:350-354, (2010).

12. Mahesh Angira ,Kamaljit Rangra, "Design and investigation of a low insertion loss, broadband, enhanced self and hold down power RF-MEMS switch" Microsystem Technol, vol. 21, pp: 1173-1178, (2015).

13. J.Y. Park, G.H. Kim, K.W. Chung, J.U. Bu, Monolithically integrated micromachined RF MEMS capacitive switches, Sens. Actuators A vol. 89 pp: 88-94, (2001)

14. S.Girish Gandhi, I.Govardhani, Sarat kumar K, "Improve the performance of a novel capacitive shunt RF MEMS switch by beam and dielectric material," IEEE Transactions on Electrical and Electronic Materials, Springer, Online ISSN 2092-7592, Oct. (2019).

15. Giridhar MS, Jambhalikar A, John J, Islam R, Nagendra CL, Alex TK, "An X band RF MEMS switch based on silicon-on-glass architecture”, Sadhana, vol:34(4),pp: 625-628,(2009). 
16. Mafinejad Kouzani A, Mafinezhad K, Hosseinnezhad $\mathrm{R}$, "Low insertion loss and high isolation capacitive RF MEMS switch with low pull-in voltage", The International Journal of Advanced Manufacturing Technology, vol. 93, pp: 661-670, (2017).

17. M Tang, A.B Yu, A.Q Liu, A. Agarwal, S. Aditya, Z.S Liu, "High Isolation X-band MEMS Capacitive Switches", Elsevier, vol. 120, pp. 95-98, (2005).

18. Jong-Man Kim, Jae-Hyoung Park, "The SIOG-Based Single-Crystalline Silicon (SCS) RF MEMS Switch with Uniform Characteristics", Journal of Micro Electro Mechanical Systems" vol. 13, pp. 1036-1042, (2004).

19. Ganesh G.V., Srinivasa Rao K. (2019), 'Design and analysis of shunt configuration-based RF MEMS switch', International Journal of Innovative Technology and Exploring Engineering, 8(9), PP.2034-2039.

20. Srinivasa Rao K., Sravya S., Varma G.S.K., Girija Sravani K. ( 2018), 'Design of low actuation voltage RF MEMS capacitive switch using serpentine flexure and rectangular perforations',Journal of Advanced Research in Dynamical and Control Systems, 10 (2),PP. 523- 528.

21. Mohan, C.L., Kavya, K.C.S. \& Kotamraju, S.K. Design, and Analysis of Capacitive Shunt RF MEMS Switch for Reconfigurable Antenna. Trans. Electr. Electron. Mater. (2020). https://doi.org/10.1007/s42341-020-00212-0

22. S. Girish Gandhi, I. Govardhani, M. Venkata Narayana, K. Sarat Kumar. "Design and performance analysis of novel bridge type RFMEMS switch for X-band", Materials Today:Proceedings, 2021 